OPEN ACCESS

Edited by:

Dick Tibboel,

Erasmus Medical Center, Netherlands

Reviewed by:

Puneet Kumar Arora,

Children's Hospital of Los Angeles,

United States

David Andrew Paul, Christiana Care Health System,

United States

*Correspondence:

Alain Cuna

accuna@cmh.edu

Specialty section:

This article was submitted to Neonatology,

a section of the journal

Frontiers in Pediatrics

Received: 24 November 2020 Accepted: 28 January 2021

Published: 18 February 2021

Citation:

Cuna A, Sampath $V$ and Khashu $M$ (2021) Racial Disparities in Necrotizing Enterocolitis. Front. Pediatr. 9:633088. doi: $10.3389 /$ fped.2021.633088

\section{Racial Disparities in Necrotizing Enterocolitis}

\author{
Alain Cuna ${ }^{1,2 *}$, Venkatesh Sampath ${ }^{1,2}$ and Minesh Khashu ${ }^{3,4}$ \\ ${ }^{1}$ School of Medicine, University of Missouri Kansas City, Kansas City, MO, United States, ${ }^{2}$ Division of Neonatology, \\ Children's Mercy Kansas City, Kansas City, MO, United States, ${ }^{3}$ Neonatal Service, University Hospitals Dorset, Poole, \\ United Kingdom, ${ }^{4}$ Bournemouth University, Dorset, United Kingdom
}

Necrotizing enterocolitis (NEC) is a serious disease of the intestinal tract affecting $5-10 \%$ of pre-term infants with up to $50 \%$ mortality in those that require surgery. There is wide variation in the rates and outcomes of NEC by race and ethnicity, and the reasons for this disparity are poorly understood. In this article, we review the epidemiology and discuss possible explanations for racial and ethnic differences in NEC. Most of the current evidence investigating the role of race in NEC comes from North America and suggests that Hispanic ethnicity and non-Hispanic Black race are associated with higher risk of NEC compared to non-Hispanic White populations. Differences in pre-term births, breastfeeding rates, and various sociodemographic factors does not fully account for the observed disparities in NEC incidence and outcomes. While genetic studies are beginning to identify candidate genes that may increase or decrease risk for NEC among racial populations, current data remain limited by small sample sizes and lack of validation. Complex interactions between social and biological determinants likely underly the differences in NEC outcomes among racial groups. Larger datasets with detailed social, phenotypic, and genotypic information, coupled with advanced bioinformatics techniques are needed to comprehensively understand racial disparities in NEC.

Keywords: newborn, prematurity, race, genetics, necrotizing enterocolitis

\section{INTRODUCTION}

Necrotizing enterocolitis (NEC) is a devastating inflammatory disease of the intestinal tract that affects $5-10 \%$ of pre-term infants born $<1,500$ grams at birth. It is the most common cause of emergency gastrointestinal surgery in the neonatal period and is the leading cause of death in preterm infants between 2 weeks and 2 months of age $(1,2)$. Several risk factors have been implicated in NEC, including prematurity, small for gestational age, formula feeding, infection, ischemia, host genetics, and gut dysbiosis (3-5). Race has also been identified as an important risk factor for NEC. In the clinical risk index tool called GutCheck ${ }^{\mathrm{NEC}}$, non-Hispanic Black or Hispanic race is one of nine independent risk factors that collectively can help identify infants at risk for developing $\operatorname{NEC}(6)$.

While recent studies suggest that rates of NEC are decreasing, the racial gap in rates and outcomes of NEC has remained unchanged $(7,8)$. The reasons for underlying racial differences in pre-term NEC outcomes are poorly understood. Racial disparities in NEC persist despite controlling for several sociodemographic factors, suggesting that more complex factors that drive racial differences in NEC are involved. A more comprehensive understanding of how these factors interact with each other is needed to craft potential solutions that reduce racial disparities in NEC. 
In this article, we review the epidemiologic evidence behind racial differences in NEC, discuss possible explanations for these differences, and examine key questions for future research. This article will focus on the disparities in NEC outcomes among nonHispanic Black, non-Hispanic White, and Hispanic infants in the United States, as these populations are the best studied in the literature.

\section{EPIDEMIOLOGY OF RACIAL DISPARITIES IN NEC}

\section{Racial Disparities in NEC Across the Globe}

Epidemiological studies of NEC from different countries provide clues regarding the contribution of race in NEC pathogenesis. In general, NEC appears to occur less frequently among pre-term infants from Japan, Switzerland, and Austria while afflicting preterm infants more often in North America, the United Kingdom, and Ireland (9). A recent study by Su et al. (10) that compared outcomes of extremely pre-term infants from Taiwan with those from other countries found that NEC rates were noticeably lower in Taiwan (3\%) and Japan (3\%) compared to Canada (8\%) and the United States (11\%). While race may explain these differences, other reasons such as variations in neonatal care practices can also explain the marked variation in NEC rates across these different countries. For example, countries with a more active approach for offering intensive care to babies at the limits of viability may have higher NEC rates because of the higher survival of extreme pre-term babies most at risk for NEC, while countries with high usage rates of breastmilk or probiotics may have lower NEC rates (11). Inconsistencies in the criteria used to define NEC may also make NEC rates vary among different countries. However, in a systematic review of NEC incidence from high income countries, Battersby et al. (11) demonstrated an almost 4-fold difference in NEC rates even among countries that used Bell staging $\geq 2$ to define NEC.

\section{Racial Disparities in NEC in the United States}

Additional evidence for the role of race in NEC comes from studies from the United States, where differences in incidence and severity of NEC based on race were observed in both single-center and regional studies where care practices and case definitions for NEC are similar (Table 1).

For example, Guner et al. (16) performed a statebased analysis of NEC outcomes in California and used multivariate analysis to demonstrate that Hispanic ethnicity was independently associated with increased odds of death from NEC with adjusted odds ratio (aOR) of 1.50 and $95 \%$ confidence interval (CI) of 1.09-2.07. Two more recent studies of infants from California also showed similar findings of higher odds of NEC among Hispanics compared to non-Hispanic White infants $(7,17)$. Another study by Llanos et al. (14) analyzed NEC epidemiology from Upstate New York and found that non-Hispanic Black neonates had significantly higher risk of NEC compared to non-Hispanic White neonates even after adjusting for birth weight with relative risk (RR) of $1.70(95 \%$
CI 1.06-2.61). A more recent study from New York that used a novel "fetus-at-risk" approach found that non-Hispanic Black infants had 4.4 times higher rate of NEC (95\% CI 2.98-6.51) compared to non-Hispanic White infants (19).

Studies using US national databases demonstrated racial differences in NEC as well. An early study by Holman et al. (13) used data from the National Center for Health Statistics to study the epidemiology of NEC infant mortality in the United States and identified that non-Hispanic Black race was associated with higher mortality rate from NEC compared to non-Hispanic White race, even after controlling for birth weight, gestational age, and other characteristics (RR 1.5, 95\% CI 1.31.8). Similar findings of increased incidence of NEC in nonHispanic Black compared to non-Hispanic White infants were found in studies using the Kids' Inpatient Database (15) and the National Institute of Child Health and Human Development Neonatal Research Network (12). In a more recent study using the Pediatrix Medical Group database, Jammeh et al. (18) demonstrated that non-Hispanic Black and Hispanic infants are (1) significantly more likely to be diagnosed with NEC, and (2) have higher odds of death from NEC, compared to non-Hispanic White infants.

\section{POSSIBLE EXPLANATIONS FOR RACIAL DISPARITIES IN NEC}

\section{Biological Risk Factors That Mediate Association Between Race and NEC}

Racial disparities in NEC can be explained by its strong association with other biological risk factors known to impact NEC (Figure 1). For example, prematurity is identified as a clear and consistent risk factor for NEC. In a 2-year national surveillance study in England, NEC incidence was 11\% among infants at 24 weeks gestation and decreased to $0.5 \%$ at 31 weeks gestation (20). Another important biologic risk factor for NEC is low birth weight. In one study from the Netherlands, small for gestational age infants have more than 2-fold increased risk for NEC compared to appropriate for gestational age neonates (21). As rates of pre-term birth and low birth weight infants are higher among non-Hispanic Black and Hispanic infants, it has been hypothesized that these factors, rather than race itself, mediate the higher rates of NEC observed in this racial population $(22,23)$. However, several studies that accounted for differences in birth weight and/or gestational age found that increased rates of NEC in non-Hispanic Black and Hispanic infants remained significant even after adjusting for these confounding factors $(7,13,14,16-18)$. Breastmilk feeding practices, a major protective factor against NEC, can also vary among different race groups. Population studies have observed that breastfeeding rates are lower among non-Hispanic Black infants compared to non-Hispanic White infants, which may help to explain the higher NEC rates among non-Hispanic Blacks $(24,25)$. The protective effect of breastmilk is highlighted in the recent study by Goldstein et al. (7) where higher odds of NEC in non-Hispanic Black infants compared to non-Hispanic White infants were no longer statistically significant when human 
TABLE 1 | Summary of studies showing racial differences in NEC-related outcomes in the United States.

\begin{tabular}{|c|c|c|c|c|}
\hline Study & Cohort characteristics & Main findings & Summary statistics & Adjustments to analysis \\
\hline Uauy et al. (12) & $\begin{array}{l}\text { 2,681 very low-birth-weight infants } \\
\text { from eight participating University } \\
\text { centers of the National Institute of } \\
\text { Child Health and Human } \\
\text { Development }\end{array}$ & $\begin{array}{l}\text { Increased odds of proven NEC } \\
\text { among non-Hispanic Black } \\
\text { compared to other male infants }\end{array}$ & aRR 2.3 (1.5-3.4) & Center \\
\hline Holman et al. (13) & $\begin{array}{l}\text { 6,629 infants who died of NEC based } \\
\text { on data from National Center for } \\
\text { Health Statistics, Centers for Disease } \\
\text { Control and Prevention }\end{array}$ & $\begin{array}{l}\text { Increased NEC-related mortality } \\
\text { among non-Hispanic Black infants }\end{array}$ & aRR 1.5 (1.3-1.8) & $\begin{array}{l}\text { Birth weight, sex, maternal } \\
\text { age }\end{array}$ \\
\hline Llanos et al. (14) & $\begin{array}{l}85 \text { infants with NEC from two regional } \\
\text { perinatal centers in Upstate New York }\end{array}$ & $\begin{array}{l}\text { Increased risk for NEC among } \\
\text { non-Hispanic Black compared to } \\
\text { non-Hispanic White infants }\end{array}$ & aRR 1.70 (1.06-2.61) & Birth weight \\
\hline Holman et al. (15) & $\begin{array}{l}\text { 4,463 hospitalizations associated with } \\
\text { NEC were studied using Kids' } \\
\text { Inpatient Database }\end{array}$ & $\begin{array}{l}\text { NEC-related hospitalization rate (per } \\
100,000 \text { live births) higher for } \\
\text { non-Hispanic Blacks than for both } \\
\text { non-Hispanic Whites and Hispanics }\end{array}$ & $\begin{array}{l}\text { Non-Hispanic Black: } 165.6 \\
(137.2-194) \\
\text { Non-Hispanic White: } \\
63.2(51.5-74.9)\end{array}$ & Not applicable \\
\hline Guner et al. (16) & $\begin{array}{l}\text { 2,318 infants with NEC from } \\
\text { California Office of Statewide Health } \\
\text { Planning and Development database }\end{array}$ & $\begin{array}{l}\text { Increased mortality among Hispanic } \\
\text { infants with NEC compared to other } \\
\text { ethnicities }\end{array}$ & aOR 1.50 (1.09-2.07) & $\begin{array}{l}\text { Birth weight, level of } \\
\text { hospital, insurance status, } \\
\text { and median household } \\
\text { income }\end{array}$ \\
\hline $\begin{array}{l}\text { Anderson et al. } \\
(17)\end{array}$ & $\begin{array}{l}245,242 \text { pre-term infants from } \\
\text { California Office of Statewide Health } \\
\text { Planning and Development database }\end{array}$ & $\begin{array}{l}\text { Hispanic infants born at 26-28 } \\
\text { weeks' gestation more likely to } \\
\text { develop NEC than non-Hispanic } \\
\text { White infants }\end{array}$ & aOR 1.32 (1.05-1.66) & $\begin{array}{l}\text { Gestational age, birth } \\
\text { weight, sex, multiple } \\
\text { gestation }\end{array}$ \\
\hline Jammeh et al. (18) & $\begin{array}{l}126,089 \text { infants from Pediatrix } \\
\text { Medical Group database }\end{array}$ & $\begin{array}{l}\text { Increased NEC incidence and NEC } \\
\text { mortality among non-Hispanic Blacks } \\
\text { and Hispanic infants compared to } \\
\text { non-Hispanic White infants }\end{array}$ & $\begin{array}{l}\text { NEC incidence } \\
\text { Non-Hispanic Black: aOR } 1.31 \\
\text { (1.25-1.39) } \\
\text { Hispanic: aOR } 1.30 \text { (1.21-1.39) } \\
\text { NEC mortality } \\
\text { Non-Hispanic Black: aOR } 1.35 \\
\text { (1.15-1.58) } \\
\text { Hispanic: aOR } 1.31 \text { (1.09-1.56) }\end{array}$ & $\begin{array}{l}\text { Birth weight, gestational } \\
\text { age, gender, size for } \\
\text { gestational age, type of } \\
\text { enteral feeding, prenatal } \\
\text { steroid exposure, ventilator } \\
\text { support, and inotropic } \\
\text { support }\end{array}$ \\
\hline Janevic et al. (19) & $\begin{array}{l}582,297 \text { infants from New York State } \\
\text { Department of Health and Human } \\
\text { Services }\end{array}$ & $\begin{array}{l}\text { Increased risk for NEC in } \\
\text { non-Hispanic Black compared to } \\
\text { non-Hispanic White infants }\end{array}$ & $\begin{array}{l}\text { Conventional approach: aRR } \\
1.52(1.10-2.11) \\
\text { Fetus-at-risk approach: aHR } \\
4.40(2.98-6.51)\end{array}$ & $\begin{array}{l}\text { Maternal age, parity, } \\
\text { educational level, insurance } \\
\text { status, sex, maternal } \\
\text { morbidities }\end{array}$ \\
\hline Goldstein et al. (7) & $\begin{array}{l}47,112 \text { infants from California } \\
\text { Perinatal Quality Care Collaborative }\end{array}$ & $\begin{array}{l}\text { Increased odds of NEC among } \\
\text { Hispanic and Asian/Pacific Islander } \\
\text { compared to non-Hispanic White } \\
\text { infants. }\end{array}$ & $\begin{array}{l}\text { Hispanic: aOR } 1.27(1.02-1.57) \\
\text { Asian or Pacific Islander: aOR } \\
1.35(1.01-1.80)\end{array}$ & $\begin{array}{l}\text { Birth year, gestational age, } \\
\text { small for gestational age, } \\
\text { multiple birth, Apgar, sex, } \\
\text { required transfer, prenatal } \\
\text { care, level of care, center, } \\
\text { human milk at discharge }\end{array}$ \\
\hline
\end{tabular}

aOR, adjusted odds ratio; aHR, adjusted hazards ratio; aRR, adjusted relative risk. Data in parentheses indicate $95 \%$ confidence intervals.

milk use was accounted for. In their mediation analysis, human milk use accounted for $44 \%$ of the total risk of NEC in nonHispanic Black vs. non-Hispanic White infants. Still, breastmilk use alone cannot account for the higher rates of NEC among Hispanics, who typically have higher breastfeeding rates than non-Hispanic Whites (26). A recent study by Gay et al. (27) also demonstrated differences in the actual composition of human milk metabolites among mothers from different countries. Whether such differences contribute to the differences in NEC rates among different racial or geographic populations remain unknown, but it is possible that the differences in breastmilk metabolites influence the infant's gut microbiota and mediate risk for NEC. Another plausible explanation is that because NEC and death are competing outcomes, the higher risk of neonatal mortality observed among non-Hispanic White pre-term infants can explain racial differences in NEC (28). In this hypothesis, non-Hispanic Black infants have higher NEC rates because of a greater number of survivors who remain at risk for NEC $(13,17,18)$.

\section{Non-biological Mediators of Racial Disparities in NEC Outcomes}

Race is also a strong proxy for social, cultural, educational, economic, and environmental experiences - all of which can influence disease risk (Figure 1). Thus, the observed racial differences in NEC may be explained by differences in nonbiologic risk factors associated with race. For example, it is well-documented that Hispanics and non-Hispanic Blacks often 


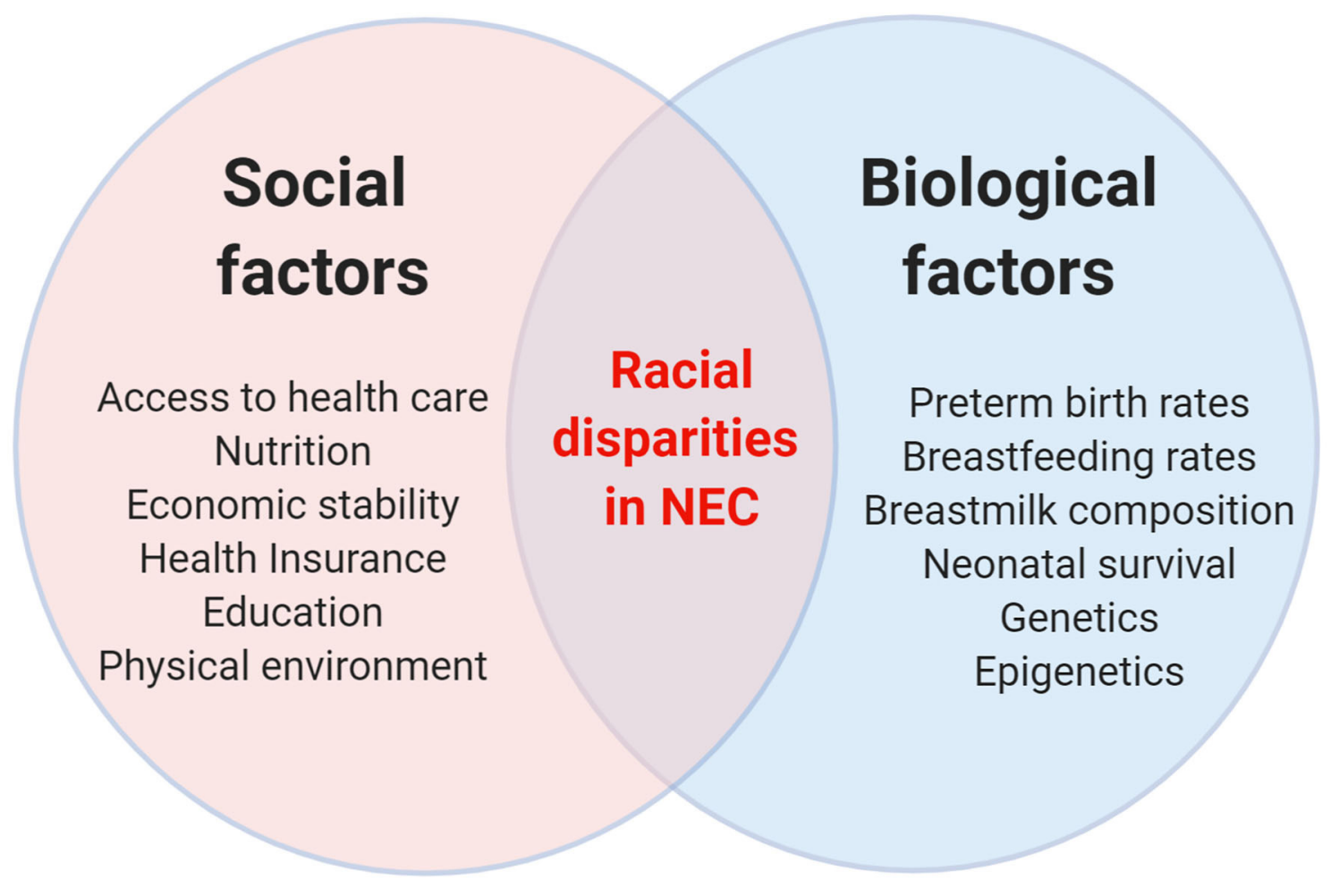

FIGURE 1 | Schematic diagram showing the interplay between social and biological factors in driving racial disparities in NEC.

have poor access to health care, including prenatal care $(29,30)$. Such racial disparities in prenatal care are important as several maternal factors have been associated with NEC, including premature rupture of membranes (31), chorioamnionitis (32), intrauterine growth restriction (33), placental abruption (34), and inadequate antenatal steroid administration for possible pre-term delivery (35). In another study, Kogan et al. (36) analyzed racial disparities in prenatal care and found that nonHispanic Black women were more likely to report not receiving advice about important topics such as breastfeeding - a wellknown protective mediator in NEC (37). Several studies have also identified inequality in the care of very low birth weight infants by race, with non-Hispanic Black and Hispanic infants receiving care at lower-quality hospitals compared to nonHispanic White infants (38-41). While the exact reasons for variation in NEC incidence and outcomes across hospitals are unclear, clinical practice variables identified in the literature as potential protective mediators of NEC risk include use of standardized feeding protocols (42), donor breast milk (43), antibiotic stewardship (44), and probiotics (45). Other related variables that can contribute to higher NEC rates include the over-representation of adverse experiences among non-Hispanic Black infants such as poverty, malnutrition, stress, pollutants, and poor education. In addition to their impact on higher pre-term birth rates (46-48), these adverse experiences may also mediate racial differences in NEC outcomes through epigenetics and the microbiome $(49,50)$.

\section{Genetic Basis of Race-Dependent Differences in NEC Vulnerability}

Another plausible explanation for the observed racial differences in NEC outcomes is that race imputes an innate biologic predisposition to NEC (Figure 1). This hypothesis is based on the assumption that different racial groups have unique patterns of genetic variations that can increase or decrease inherent risk for certain diseases (51). Genome wide sequencing studies evince that non-Hispanic Black populations have more heterozygote genotypes as well as more non-synonymous variants per individual compared to other racial populations $(52,53)$. Interestingly, selection pressures arising from infectious disease exposure has resulted in the non-Hispanic Black race having a stronger inflammatory response to pathogens (54). In adults, genetic programming of the immune response contributes up to a 3-fold difference in susceptibility to tuberculosis, septicemia and inflammatory diseases between non-Hispanic Black and non-Hispanic White populations $(55,56)$. Remarkably, NEC is also postulated to arise from an exaggerated inflammatory response to gut microbiota, and therefore racial differences in NEC vulnerability may be genetically programmed $(4,57)$.

Genetic studies in NEC have often been limited by small sample sizes and homogenous study populations with little racial diversity, limiting meaningful subgroup analysis by racial groups. One study by Franklin et al. (58) evaluated the association of several pro-inflammatory cytokine gene polymorphisms with $\mathrm{NEC}$ in a racially diverse population of pre-term infants from a 
single center in Washington, DC, and found that non-Hispanic White neonates with the C allele of IL-6 (rs1800795) were over 6 times more likely to have NEC than those with no $\mathrm{C}$ allele ( $p=0.013$; OR $=6.61,95 \%$ CI 1.48-29.39). Another study by Sampath et al. (59) investigated autophagy genes in a multicenter cohort $(n=1,015)$ of pre-term infants with and without NEC and identified that the ATG16L1 (rs2241880, Thr300Ala) variant was associated with NEC. Risk of NEC was highest among infants with the AA genotype and decreased proportionately with the addition of the G allele (AA vs. GG: OR 2.5, 95\% CI 1.25.6). In evaluating genetic differences along racial groups, the authors found that the proportion of infants with the protective GG allele was lower in non-Hispanic Black infants compared to non-Hispanic White infants (13 vs. $25 \%$ ). Similarly, in another small study, NEC rates were higher in non-Hispanic Black preterm infants, and correlated with higher prevalence of the NECassociated NFKB1 (g.-24519delATTG) variant in that race (60).

These studies suggest that genetic variants which program increased inflammation are enriched in certain racial groups and may explain racial differences in NEC. Yet completion of the Human Genome Project has highlighted how humans are more similar than different from each other, and an ongoing debate remains about the importance of racial differences in genetic effects for disease (61-63). Comprehensive studies incorporating genetic, functional and clinical/demographic variables are required to characterize race-specific susceptible and resilience genetic factors.

\section{DISCUSSION}

While socioeconomic differences between races account for a substantial portion of racial disparity in health outcomes (64), adjusting for socioeconomic differences does not completely eliminate racial disparities in NEC. For example, Guner et al. (16) evaluated the contribution of household income and insurance status to differences in mortality from NEC in California and concluded that these socioeconomic factors could not explain the disparities in NEC mortality between Hispanic and non-Hispanic infants. Similarly, Janevic et al. (19) found that the increased risk among non-Hispanic Black infants for NEC remained despite including maternal educational level, insurance level, and other potential socioeconomic factors in their analysis of pre-term infants from New York. An important limitation of these studies that adjust for socioeconomic differences is the potential for unmeasured confounding by important variables that were not known or recorded in the original study database (65). Socioeconomic status is also difficult to measure, and misclassification or measurement errors in socioeconomic status are not uncommon $(66,67)$. Despite these limitations, these studies suggest that while social factors of race are certainly key contributors, these factors alone do not account for all the racial differences in NEC.

The contribution of genetic sequence differences between racial groups on risk of diseases such as NEC is also poorly understood (68). Emerging genetic studies of susceptibility to infection suggest that genetic variations can contribute to the host-inflammatory immune response (69-71). While some genetic studies in NEC have shown similar enrichment of proinflammatory genetic variants along racial groups, these studies should be considered exploratory and hypothesis-generating at best due to the limited sample size and lack of validation or functional studies $(4,72)$. The epigenetic effects of social and environmental factors on expression of key genes involved in NEC pathogenesis are also largely unexplored (73-75).

A better understanding of the contribution of race in NEC pathogenesis is needed to improve the racial disparities in NEC outcomes. Race is a complex trait that encompasses several social determinants and may also have important genetic underpinnings that contribute to NEC. In the search for a better understanding of how race impacts NEC, it is important to remember its multifaceted nature and avoid narrowly focusing on a single aspect while ignoring the rest.

\section{CONCLUSION}

There is consistent epidemiological evidence for racial differences in NEC incidence and severity. While genetic variations across racial groups may result in biological effects that impact NEC pathogenesis, current genetic studies remain inadequate to prove or disprove this hypothesis. Race is a complex trait encompassing social, cultural, behavioral, and environmental dimensions that impact health and disease (76). In exploring racial differences in NEC, it is important to fully evaluate how both biological and nonbiological aspects of race influence NEC pathogenesis independently as well as how they interact with each other. Alongside these research efforts, public health and quality improvement initiatives should also continue to actively reduce racial disparities in neonatal and perinatal care to improve outcomes.

\section{AUTHOR CONTRIBUTIONS}

$\mathrm{AC}$ and MK conceptualized the study. AC wrote the first draft of the manuscript. VS critically reviewed the manuscript and wrote the genetics section. All authors contributed to manuscript revision, read, and approved the submitted version.

\section{FUNDING}

This work was supported by institutional funds at Children's Mercy Hospital (VS, AC) and the National Institute of Health R01DK117296 (VS) and K08DK125735 (AC).

\section{ACKNOWLEDGMENTS}

Editorial assistance was provided by the Medical Writing Center at Children's Mercy Kansas City. Figure 1 was created using Biorender.com. 


\section{REFERENCES}

1. Henry MC, Lawrence Moss R. Surgical therapy for necrotizing enterocolitis: bringing evidence to the bedside. Semin Pediatr Surg. (2005) 14:18190. doi: 10.1053/j.sempedsurg.2005.05.007

2. Patel RM, Kandefer S, Walsh MC, Bell EF, Carlo WA, Laptook AR, et al. Causes and timing of death in extremely premature infants from 2000 through 2011. N Engl J Med. (2015) 372:331-40. doi: 10.1056/NEJMoa 1403489

3. Samuels N, van de Graaf RA, de Jonge RCJ, Reiss IKM, Vermeulen MJ. Risk factors for necrotizing enterocolitis in neonates: a systematic review of prognostic studies. BMC Pediatr. (2017) 17:105. doi: 10.1186/s12887-017-0847-3

4. Cuna A, George L, Sampath V. Genetic predisposition to necrotizing enterocolitis in premature infants: current knowledge, challenges, and future directions. Semin Fetal Neonatal Med. (2018) 23:387-93. doi: 10.1016/j.siny.2018.08.006

5. Caplan MS, Underwood MA, Modi N, Patel R, Gordon PV, Sylvester KG, et al. Necrotizing enterocolitis: using regulatory science and drug development to improve outcomes. J Pediatr. (2019) 212:208-15.e1. doi: 10.1016/j.jpeds.2019.05.032

6. Gephart SM, Spitzer AR, Effken JA, Dodd E, Halpern M, McGrath JM. Discrimination of GutCheck(NEC): a clinical risk index for necrotizing enterocolitis. J Perinatol. (2014) 34:468-75. doi: 10.1038/jp. 2014.37

7. Goldstein GP, Pai VV, Liu J, Sigurdson K, Vernon LB, Lee HC, et al. Racial/ethnic disparities and human milk use in necrotizing enterocolitis. Pediatric Res. (2020) 88(Suppl 1):3-9. doi: 10.1038/s41390-0201073-5

8. Travers CP, Carlo WA, McDonald SA, Das A, Ambalavanan N, Bell EF, et al. Racial/ethnic disparities among extremely preterm infants in the United States from 2002 to 2016. JAMA Network Open. (2020) 3:e206757. doi: 10.1001/jamanetworkopen.2020.6757

9. Foldvari M. Observations of membrane fusion in a liposome dispersion: the missing fusion intermediate? F1000Res. (2015) 4:4. doi: 10.12688/f1000research.6003.2

10. Su BH, Hsieh WS, Hsu $\mathrm{CH}$, Chang $\mathrm{JH}$, Lien $\mathrm{R}$, Lin $\mathrm{CH}$, et al. Neonatal outcomes of extremely preterm infants from taiwan: comparison with Canada, Japan, and the USA. Pediatr Neonatol. (2015) 56:4652. doi: 10.1016/j.pedneo.2014.05.002

11. Battersby C, Santhalingam T, Costeloe K, Modi N. Incidence of neonatal necrotising enterocolitis in high-income countries: a systematic review. Arch Dis Child Fetal Neonatal Ed. (2018) 103:F182-F9. doi: 10.1136/archdischild-2017-313880

12. Uauy RD, Fanaroff AA, Korones SB, Phillips EA, Phillips JB, Wright LL. Necrotizing enterocolitis in very low birth weight infants: biodemographic and clinical correlates. National institute of child health and human development neonatal research network. J Pediatr. (1991) 119:6308. doi: 10.1016/S0022-3476(05)82418-7

13. Holman RC, Stoll BJ, Clarke MJ, Glass RI. The epidemiology of necrotizing enterocolitis infant mortality in the United States. Am J Public Health. (1997) 87:2026-31. doi: 10.2105/AJPH.87.12.2026

14. Llanos AR, Moss ME, Pinzon MC, Dye T, Sinkin RA, Kendig JW. Epidemiology of neonatal necrotising enterocolitis: a population-based study. Paediatr Perinat Epidemiol. (2002) 16:342-9. doi: 10.1046/j.1365-3016.2002.00445.x

15. Holman RC, Stoll BJ, Curns AT, Yorita KL, Steiner CA, Schonberger LB. Necrotising enterocolitis hospitalisations among neonates in the United States. Paediatr Perinat Epidemiol. (2006) 20:498-506. doi: 10.1111/j.1365-3016.2006.00756.x

16. Guner YS, Friedlich P, Wee CP, Dorey F, Camerini V, Upperman JS. Statebased analysis of necrotizing enterocolitis outcomes. J Surg Res. (2009) 157:21-9. doi: 10.1016/j.jss.2008.11.008

17. Anderson JG, Rogers EE, Baer RJ, Oltman SP, Paynter R, Partridge JC, et al. Racial and ethnic disparities in preterm infant mortality and severe morbidity: a population-based study. Neonatology. (2018) 113:4454. doi: $10.1159 / 000480536$
18. Jammeh ML, Adibe OO, Tracy ET, Rice HE, Clark RH, Smith PB, et al. Racial/ethnic differences in necrotizing enterocolitis incidence and outcomes in premature very low birth weight infants. J Perinatol. (2018) 38:138690. doi: 10.1038/s41372-018-0184-x

19. Janevic T, Zeitlin J, Auger N, Egorova NN, Hebert P, Balbierz A, et al. Association of race/ethnicity with very preterm neonatal morbidities. JAMA Pediatrics. (2018) 172:1061-9. doi: 10.1001/jamapediatrics.2018.2029

20. Battersby C, Longford N, Mandalia S, Costeloe K, Modi N, group UKNCNEs. Incidence and enteral feed antecedents of severe neonatal necrotising enterocolitis across neonatal networks in England, 2012-13: a wholepopulation surveillance study. Lancet Gastroenterol Hepatol. (2017) 2:4351. doi: 10.1016/S2468-1253(16)30117-0

21. Ree IM, Smits-Wintjens VE, Rijntjes-Jacobs EG, Pelsma IC, Steggerda SJ, Walther FJ, et al. Necrotizing enterocolitis in small-for-gestationalage neonates: a matched case-control study. Neonatology. (2014) 105:748. doi: $10.1159 / 000356033$

22. Manuck TA. Racial and ethnic differences in preterm birth: a complex, multifactorial problem. Semin Perinatol. (2017) 41:511-8. doi: 10.1053/j.semperi.2017.08.010

23. Martin JA, Hamilton BE, Osterman MJ, Driscoll AK, Mathews TJ. Births: final data for 2015. Natl Vital Stat Rep. (2017) 66:1. Available online at: https://www. cdc.gov/nchs/data/nvsr/nvsr66/nvsr66_01.pdf

24. Bartick MC, Jegier BJ, Green BD, Schwarz EB, Reinhold AG, Stuebe AM. Disparities in breastfeeding: impact on maternal and child health outcomes and costs. J Pediatr. (2017) 181:49-55.e6. doi: 10.1016/j.jpeds.2016.10.028

25. McDowell MM, Wang CY, Kennedy-Stephenson J. Breastfeeding in the United States: findings from the national health and nutrition examination surveys, 1999-2006. NCHS Data Brief. (2008) 1-8. doi: 10.1037/e455822008-001

26. McKinney CO, Hahn-Holbrook J, Chase-Lansdale PL, Ramey SL, Krohn J, Reed-Vance $M$, et al. Racial and ethnic differences in breastfeeding. Pediatrics. (2016) 138:e20152388. doi: 10.1542/peds.20 15-2388

27. Gay MCL, Koleva PT, Slupsky CM, Toit ED, Eggesbo M, Johnson CC, et al. Worldwide variation in human milk metabolome: indicators of breast physiology and maternal lifestyle? Nutrients. (2018) 10:1151. doi: $10.3390 /$ nu10091151

28. Alexander GR, Kogan M, Bader D, Carlo W, Allen M, Mor J. US birth weight/gestational age-specific neonatal mortality: 19951997 rates for whites, hispanics, and blacks. Pediatrics. (2003) 111:e61-6. doi: 10.1542/peds.111.1.e61

29. Fiscella K, Sanders MR. Racial and ethnic disparities in the quality of health care. Annu Rev Public Health. (2016) 37:37594. doi: 10.1146/annurev-publhealth-032315-021439

30. Wheeler SM, Bryant AS. Racial and ethnic disparities in health and health care. Obstet Gynecol Clin North Am. (2017) 44:1-11. doi: 10.1016/j.ogc.2016.10.001

31. Ahle M, Drott P, Elfvin A, Andersson RE. Maternal, fetal and perinatal factors associated with necrotizing enterocolitis in Sweden. A national casecontrol study. PLoS ONE. (2018) 13:e0194352. doi: 10.1371/journal.pone. 0194352

32. Been JV, Lievense S, Zimmermann LJ, Kramer BW, Wolfs TG. Chorioamnionitis as a risk factor for necrotizing enterocolitis: a systematic review and meta-analysis. J Pediatr. (2013) 162:236-42 e2. doi: 10.1016/j.jpeds.2012.07.012

33. Garite TJ, Clark R, Thorp JA. Intrauterine growth restriction increases morbidity and mortality among premature neonates. Am J Obstet Gynecol. (2004) 191:481-7. doi: 10.1016/j.ajog.2004. 01.036

34. Luig M, Lui K, Nsw, Group AN. Epidemiology of necrotizing enterocolitispart II: risks and susceptibility of premature infants during the surfactant era: a regional study. J Paediatr Child Health. (2005) 41:174-9. doi: 10.1111/j.1440-1754.2005.00583.x

35. Roberts D, Brown J, Medley N, Dalziel SR. Antenatal corticosteroids for accelerating fetal lung maturation for women at risk of preterm birth. Cochrane Database Syst Rev. (2017) 3:CD004454. doi: 10.1002/14651858.CD004454.pub3 
36. Kogan MD, Kotelchuck M, Alexander GR, Johnson WE. Racial disparities in reported prenatal care advice from health care providers. Am J Public Health. (1994) 84:82-8. doi: 10.2105/AJPH.84.1.82

37. Altobelli E, Angeletti PM, Verrotti A, Petrocelli R. The impact of human milk on necrotizing enterocolitis: a systematic review and meta-analysis. Nutrients. (2020) 12:1322. doi: 10.3390/nu12051322

38. Howell EA, Hebert P, Chatterjee S, Kleinman LC, Chassin MR. Black/white differences in very low birth weight neonatal mortality rates among New York City hospitals. Pediatrics. (2008) 121:e407-15. doi: 10.1542/peds.20 07-0910

39. Horbar JD, Edwards EM, Greenberg LT, Profit J, Draper D, Helkey D, et al. Racial segregation and inequality in the neonatal intensive care unit for very low-birth-weight and very preterm infants. JAMA Pediatrics. (2019) 173:455-61. doi: 10.1001/jamapediatrics.2019.0241

40. Profit J, Gould JB, Bennett M, Goldstein BA, Draper D, Phibbs CS, et al. Racial/ethnic disparity in NICU quality of care delivery. Pediatrics. (2017) 140:e20170918. doi: 10.1542/peds.2017-0918

41. Howell EA, Janevic T, Hebert PL, Egorova NN, Balbierz A, Zeitlin J. Differences in morbidity and mortality rates in black, white, and hispanic very preterm infants among New York city hospitals. JAMA Pediatrics. (2018) 172:269-77. doi: 10.1001/jamapediatrics.2017.4402

42. Viswanathan S, McNelis K, Super D, Einstadter D, Groh-Wargo S, Collin M. Standardized slow enteral feeding protocol and the incidence of necrotizing enterocolitis in extremely low birth weight infants. JPEN J Parenter Enteral Nutr. (2015) 39:644-54. doi: 10.1177/0148607114 552848

43. Kantorowska A, Wei JC, Cohen RS, Lawrence RA, Gould JB, Lee HC. Impact of donor milk availability on breast milk use and necrotizing enterocolitis rates. Pediatrics. (2016) 137:e20153123. doi: 10.1542/peds.20 15-3123

44. Esmaeilizand R, Shah PS, Seshia M, Yee W, Yoon EW, Dow K, et al. Antibiotic exposure and development of necrotizing enterocolitis in very preterm neonates. Paediatr Child Health. (2018) 23:e56-e61. doi: 10.1093/pch/ pxx169

45. Morgan RL, Preidis GA, Kashyap PC, Weizman AV, Sadeghirad B, McMaster Probiotic P, et al. Probiotics reduce mortality and morbidity in preterm, low-birth-weight infants: a systematic review and network meta-analysis of randomized trials. Gastroenterology. (2020) 159:46780. doi: 10.1053 /j.gastro.2020.05.096

46. Dietze TR, Rose FF, Moore TA. Maternal variables associated with physiologic stress and perinatal complications in preterm infants. J Neonatal Perinatal Med. (2016) 9:271-7. doi: 10.3233/NPM-16915134

47. DeFranco EA, Lian M, Muglia LA, Schootman M. Area-level poverty and preterm birth risk: a population-based multilevel analysis. BMC Public Health. (2008) 8:316. doi: 10.1186/1471-2458-8-316

48. Cantarutti A, Franchi M, Monzio Compagnoni M, Merlino L, Corrao G. Mother's education and the risk of several neonatal outcomes: an evidence from an Italian population-based study. BMC Pregnancy Childbirth. (2017) 17:221. doi: 10.1186/s12884-017-1418-1

49. Burris HH, Baccarelli AA, Wright RO, Wright RJ. Epigenetics: linking social and environmental exposures to preterm birth. Pediatr Res. (2016) 79:13640. doi: 10.1038/pr.2015.191

50. Harrison CA, Taren D. How poverty affects diet to shape the microbiota and chronic disease. Nat Rev Immunol. (2018) 18:279-87. doi: 10.1038/nri.2017.121

51. Collins FS. What we do and don't know about 'race', 'ethnicity', genetics and health at the dawn of the genome era. Nat Genet. (2004) 36(Suppl. 11):S13-5. doi: 10.1038/ng1436

52. Tennessen JA, Bigham AW, O'Connor TD, Fu W, Kenny EE, Gravel S, et al. Evolution and functional impact of rare coding variation from deep sequencing of human exomes. Science. (2012) 337:64-9. doi: 10.1126/science.1219240

53. Lohmueller KE, Indap AR, Schmidt S, Boyko AR, Hernandez RD, Hubisz MJ, et al. Proportionally more deleterious genetic variation in European than in African populations. Nature. (2008) 451:994-7. doi: 10.1038/nature 06611

54. Nedelec Y, Sanz J, Baharian G, Szpiech ZA, Pacis A, Dumaine $\mathrm{A}$, et al. Genetic ancestry and natural selection drive population differences in immune responses to pathogens. Cell. (2016) 167:657-69.e21. doi: 10.1016/j.cell.2016.09.025

55. Pennington R, Gatenbee C, Kennedy B, Harpending H, Cochran G. Group differences in proneness to inflammation. Infect Genet Evol. (2009) 9:137180. doi: 10.1016/j.meegid.2009.09.017

56. Brinkworth JF, Barreiro LB. The contribution of natural selection to present-day susceptibility to chronic inflammatory and autoimmune disease. Curr Opin Immunol. (2014) 31:66-78. doi: 10.1016/j.coi.2014. 09.008

57. Hackam DJ, Sodhi CP. Toll-like receptor-mediated intestinal inflammatory imbalance in the pathogenesis of necrotizing enterocolitis. Cell Mol Gastroenterol Hepatol. (2018) 6:229-38 e1. doi: 10.1016/j.jcmgh.2018. 04.001

58. Franklin AL, Said M, Cappiello CD, Gordish-Dressman H, Tatari-Calderone Z, Vukmanovic S, et al. Are immune modulating single nucleotide polymorphisms associated with necrotizing enterocolitis? Sci Rep. (2015) 5:18369. doi: 10.1038/srep 18369

59. Sampath V, Bhandari V, Berger J, Merchant D, Zhang L, Ladd M et al. A functional ATG16L1 (T300A) variant is associated with necrotizing enterocolitis in premature infants. Pediatr Res. (2017) 81:582-8. doi: 10.1038/pr.2016.260

60. Sampath V, Le M, Lane L, Patel AL, Cohen JD, Simpson PM, et al. The NFKB1 (g.-24519delATTG) variant is associated with necrotizing enterocolitis (NEC) in premature infants. J Surg Res. (2011) 169:e517. doi: $10.1016 /$ j.jss.2011.03.017

61. Yudell M, Roberts D, DeSalle R, Tishkoff S. Science and society. Taking race out of human genetics. Science. (2016) 351:564-5. doi: 10.1126/science.aac4951

62. Foster MW, Sharp RR. Beyond race: towards a whole-genome perspective on human populations and genetic variation. Nat Rev Genet. (2004) 5:7906. doi: $10.1038 / \operatorname{nrg} 1452$

63. Cooper RS. Race in biological and biomedical research. Cold Spring Harb Perspect Med. (2013) 3:a008573. doi: 10.1101/cshperspect. a008573

64. Peyvandi S, Baer RJ, Moon-Grady AJ, Oltman SP, Chambers CD, Norton ME, et al. Socioeconomic mediators of racial and ethnic disparities in congenital heart disease outcomes: a population-based study in California. J Am Heart Assoc. (2018) 7:e010342. doi: 10.1161/JAHA.118.010342

65. Nuru-Jeter AM, Michaels EK, Thomas MD, Reeves AN, Thorpe RJ Jr, LaVeist TA. Relative roles of race versus socioeconomic position in studies of health inequalities: a matter of interpretation. Annu Rev Public Health. (2018) 39:169-88. doi: 10.1146/annurev-publhealth-040617-014230

66. Fewell Z, Davey Smith G, Sterne JA. The impact of residual and unmeasured confounding in epidemiologic studies: a simulation study. Am J Epidemiol. (2007) 166:646-55. doi: 10.1093/aje/kwm165

67. Morgenstern H. Defining and explaining race effects. Epidemiology. (1997) 8:609-11. doi: 10.1097/00001648-199711000-00002

68. Ioannidis JP, Ntzani EE, Trikalinos TA. 'Racial' differences in genetic effects for complex diseases. Nat Genet. (2004) 36:1312-8. doi: 10.1038/ ng1474

69. Carter-Timofte ME, Jorgensen SE, Freytag MR, Thomsen MM, Brinck Andersen NS, Al-Mousawi A, et al. Deciphering the role of host genetics in susceptibility to severe COVID-19. Front Immunol. (2020) 11:1606. doi: 10.3389/fimmu.2020.01606

70. Casanova JL, Abel L. The human genetic determinism of life-threatening infectious diseases: genetic heterogeneity and physiological homogeneity? Hum Genet. (2020) 139:681-94. doi: 10.1007/s00439-020-02184-w

71. Quach H, Rotival M, Pothlichet J, Loh YE, Dannemann M, Zidane $\mathrm{N}$, et al. Genetic adaptation and neandertal admixture shaped the immune system of human populations. Cell. (2016) 167:643-56.e17. doi: 10.1016/j.cell.2016.09.024

72. Cuna A, Sampath V. Genetic alterations in necrotizing enterocolitis. Semin Perinatol. (2016) 41:61-9. doi: 10.1053/j.semperi.2016. 09.019

73. Cortese R, Lu L, Yu Y, Ruden D, Claud EC. Epigenome-microbiome crosstalk: a potential new paradigm influencing neonatal susceptibility to disease. Epigenetics. (2016) 11:205-15. doi: 10.1080/15592294.2016. 1155011 
74. Gao F, Zhang J, Jiang P, Gong D, Wang JW, Xia Y, et al. Marked methylation changes in intestinal genes during the perinatal period of preterm neonates. BMC Genomics. (2014) 15:716. doi: 10.1186/1471-2164-15-716

75. Sureshchandra S, Wilson RM, Rais M, Marshall NE, Purnell JQ, Thornburg $\mathrm{KL}$, et al. Maternal pregravid obesity remodels the DNA methylation landscape of cord blood monocytes disrupting their inflammatory program. J Immunol. (2017) 199:2729-44. doi: 10.4049/jimmunol.1700434

76. Burris HH, Hwang SS, Collins JW, Jr, Kirpalani H, Wright CJ. Reconceptualizing associations between race and morbidities of extreme prematurity. J Pediatr. (2019) 207:10-4.e1. doi: 10.1016/j.jpeds.2018. 12.052
Conflict of Interest: The authors declare that the research was conducted in the absence of any commercial or financial relationships that could be construed as a potential conflict of interest.

Copyright (๑) 2021 Cuna, Sampath and Khashu. This is an open-access article distributed under the terms of the Creative Commons Attribution License (CC BY). The use, distribution or reproduction in other forums is permitted, provided the original author(s) and the copyright owner(s) are credited and that the original publication in this journal is cited, in accordance with accepted academic practice. No use, distribution or reproduction is permitted which does not comply with these terms. 